\title{
Effect of LXR/RXR agonism on brain and CSF $A \beta 40$ levels in
}

\section{rats [version 1; peer review: 1 approved, 1 approved with}

\section{reservations]}

\section{Songli Wang ${ }^{1}$, Paul Wen², Stephen Wood²}

${ }^{1}$ Genome Analysis Unit, Amgen Inc., San Francisco, CA, USA

${ }^{2}$ Deptartment of Neuroscience, Amgen Inc., Thousand Oaks, CA, USA

V1 First published: 04 Feb 2016, 5:138

https://doi.org/10.12688/f1000research.7868.1

Latest published: 19 Apr 2016, 5:138

https://doi.org/10.12688/f1000research.7868.2

\section{Abstract}

Alzheimer's disease (AD) is characterized pathologically by the presence of amyloid plaques and neurofibrillary tangles. The amyloid hypothesis contends that the abnormal accumulation of $A \beta$, the principal component of amyloid plaques, plays an essential role in initiating the disease. Impaired clearance of soluble $A \beta$ from the brain, a process facilitated by apolipoprotein E (APOE), is believed to be a contributing factor in plaque formation. APOE expression is transcriptionally regulated through the action of a family of nuclear receptors including the peroxisome proliferator-activated receptor gamma and liver $X$ receptors (LXRs) in coordination with retinoid $X$ receptors (RXRs). It has been previously reported that various agonists of this receptor family can influence brain $A \beta$ levels in rodents. In this study we investigated the effects of LXR/RXR agonism on brain and cerebrospinal fluid (CSF) levels of $A \beta 40$ in naïve rats. Treatment of rats for 3 days or 7 days with the LXR agonist, T0901317 or the RXR agonist, Bexarotene did not result in significant changes in brain or CSF A 40 levels.

\section{Keywords}

Alzheimer's , Apolipoprotein $E$, $A \beta$, liver $X$ receptor , retinoid $X$ receptor, Bexarotene

\section{Dii}

This article is included in the Preclinical

Reproducibility and Robustness gateway.

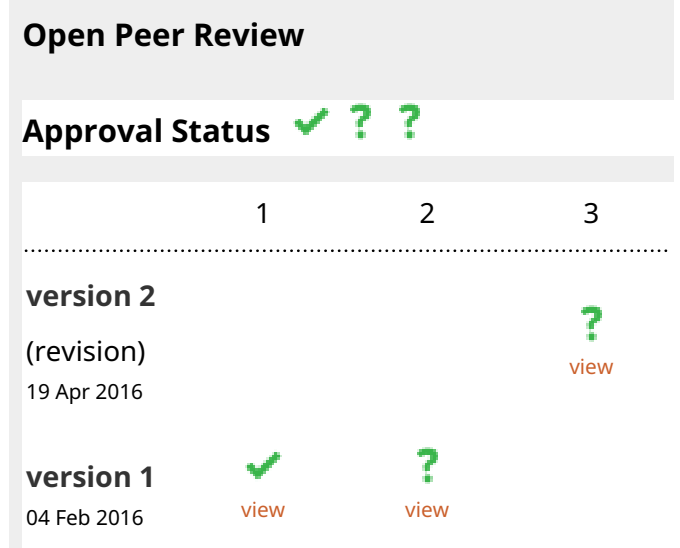

1. Sam Gandy , Mount Sinai School of Medicine, New York, USA

2. Mary Jo LaDu, University of Illinois at Chicago, Chicago, USA

Ana Valencia, University of Illinois at Chicago, Chicago, USA

Conor Smith, University of Illinois at Chicago, Chicago, USA

3. Daniel M. Michaelson, Tel Aviv University,

Tel Aviv, Israel

Any reports and responses or comments on the article can be found at the end of the article. 
Corresponding author: Stephen Wood (stephenw@amgen.com)

Competing interests: All authors are employees and stockholders of Amgen, Inc.

Grant information: All work was funded by Amgen Inc.

Copyright: @ 2016 Wang $S$ et al. This is an open access article distributed under the terms of the Creative Commons Attribution License, which permits unrestricted use, distribution, and reproduction in any medium, provided the original work is properly cited.

How to cite this article: Wang S, Wen P and Wood S. Effect of LXR/RXR agonism on brain and CSF Aß40 levels in rats [version 1; peer review: 1 approved, 1 approved with reservations] F1000Research 2016, 5:138 https://doi.org/10.12688/f1000research.7868.1

First published: 04 Feb 2016, 5:138 https://doi.org/10.12688/f1000research.7868.1 


\section{Introduction}

Alzheimer's disease (AD) is a debilitating neurodegenerative disease and the leading cause of dementia in the elderly. It is currently estimated that 5 million people in the US and 30 million worldwide are afflicted with this disease. The pathological hallmarks of AD are the presence of extracellular amyloid plaques and intracellular neurofibrillary tangles in the hippocampus and cortical areas of the brain ${ }^{1}$. The core constituent of the amyloid plaques is a $4 \mathrm{kDa}$ peptide known as amyloid- $\beta$ peptide $(\mathrm{A} \beta)$. Aggregation of $A \beta$ into soluble, multimeric assemblies and insoluble amyloid fibrils is hypothesized to contribute directly to the pathogenesis of $\mathrm{AD}$; therefore therapeutic strategies aimed at lowering soluble $\mathrm{A} \beta$ levels in the brain would be predicted to have a disease-modifying effect $^{2}$.

The E4 allele of apolipoprotein E (APOE) is the largest genetic risk factor for sporadic, late-onset AD. The presence of a single copy of E4 increases the risk for Alzheimer's disease 3-fold and individuals with 2 copies are 15 times more likely to develop $\mathrm{AD}^{3}$. Data showing that APOE4 carriers begin to accumulate amyloid deposits earlier in life relative to non-carriers ${ }^{4}$ has led to the hypothesis that increased risk associated with an E4 genotype may be the result of the effects of APOE on A $\beta$ production, turnover and/or clearance from the central nervous system (CNS).

The expression of genes encoding lipid-transport proteins, including APOE is transcriptionally regulated by the ligand-activated nuclear receptors, peroxisome proliferator-activated receptor gamma (PPAR $\gamma$ ) and liver $\mathrm{X}$ receptors (LXRs) which form obligate heterodimers with retinoid $\mathrm{X}$ receptors (RXRs) ${ }^{5}$. Additionally, activation of these receptors has been shown to affect the activation state of macrophage and microglia ${ }^{6}$. Based on the processes influenced by this nuclear receptor family it is a reasonable hypothesis that agonism of one or more members of the family could have beneficial effects on $A \beta$ homeostasis in the CNS. In fact, several groups have demonstrated that agonism of the LXR receptor resulted in reduced amyloid plaque burden and/or soluble $A \beta$ levels in amyloid precursor protein (APP) transgenic mouse models ${ }^{7-9}$. More recently it was reported that a highly selective, blood-brain barrier-permeant, RXR agonist, Bexarotene (Targretin), resulted in enhanced clearance of soluble A $\beta$ in an APP transgenic mouse model in an APOE-dependent manner. In addition, $A \beta$ plaque burden was reduced more than $50 \%$ within 72 hours. Further, Bexarotene treatment also resulted in a similar reduction $(\sim 25 \%)$ in brain interstitial fluid (ISF) levels of $\mathrm{A} \beta$ in non-transgenic, $\mathrm{C} 57 \mathrm{Bl} / 6$ mice 7-12 hours following a single administration ${ }^{10}$.

In the following study, we sought to examine the effects of LXR/RXR agonism on $\mathrm{A} \beta$ homeostasis in the CNS of non-transgenic rats using the RXR agonist, Bexarotene and the LXR agonist, TO901317.

\section{Materials and methods}

In vivo pharmacodynamic studies: All procedures were approved by the Amgen Institutional Animal Care and Use Committee. Young male Sprague-Dawley rats (175-200 g) were purchased from Harlan (Indianapolis, IN) and were maintained on a $12 \mathrm{~h}$ light/dark cycle with unrestricted access to food and water until use. Rats were dosed orally for 3 and 7 consecutive days with AMG8155, a proprietary small molecule BACE1 inhibitor, at $3 \mathrm{mg} / \mathrm{kg}$ in $2 \% \mathrm{HPMC}$ and $1 \%$ Tween 80, pH 2, Bexarotene (Alfa Aesar, Ward Hill, MA) at $100 \mathrm{mg} / \mathrm{kg}$ in $30 \%$ Labrasol, $1 \%$ Tween $20,2 \%$ Providone and $0.05 \%$ BHA, pH7.0 (Vehicle 3), and TO901317, a LXR agonist (Fisher Scientific, Pittsburgh, PA), at $30 \mathrm{mg} / \mathrm{kg}$ in $0.5 \% \mathrm{NaCl}, 2 \%$ Tween 80 (Vehicle 4). 4 hours post dose on the last day of study, rats were euthanized with $\mathrm{CO}_{2}$ inhalation for 2 minutes and the cisterna magna was quickly exposed by removing the skin and muscle above it. Cerebrospinal fluid (CSF) was collected with a 30 gauge needle inserted through the dura membrane covering the cisterna magna. CSF samples with visible blood contamination were discarded. Blood was withdrawn by cardiac puncture and plasma was obtained by centrifugation at $15,000 \mathrm{rpm}$ for $10 \mathrm{~min}$ at $4^{\circ} \mathrm{C}$ for drug exposure. Brains were removed and, along with the CSF, immediately frozen on dry ice and stored at $-80^{\circ} \mathrm{C}$ until use. The frozen brains were subsequently homogenized in 10 volumes (w/v) of $0.5 \%$ Triton X-100 in TBS with protease inhibitors cocktails. The homogenates were centrifuged at $355,000 \mathrm{rpm}$ for $30 \mathrm{~min}$ at $4^{\circ} \mathrm{C}$.

Quantification of AB40 and APOE in brain and CSF: Samples are analyzed for A $\beta$ levels by immunoassay with a MSD imager. Briefly, 96-well avidin plates (MesoScale Discovery, Inc., Gaithersburg, MD) were coated with biotinylated-anti-A $\beta$ antibody 4G8 (mouse monoclonal, Cat\# Sig 39240-1000, Covance Research Products, Princeton, NJ) at $10 \mu \mathrm{g} / \mathrm{ml}$ in PBS. Samples were co-incubated in the plate overnight at $4^{\circ} \mathrm{C}$ along with a rutheniumlabeled anti-A $\beta$ antibody specific for the $\mathrm{C}$-terminal region of A $\beta 40$ (ConFab40; Amgen, Thousand Oaks, CA). Plates were then washed, $150 \mu \mathrm{l} /$ well read buffer $\mathrm{T}$ (MesoScale Discovery, Inc.) was added, and plates were read immediately on a Sector 6000 imager according to the manufacturer's recommended protocol (MesoScale Discovery, Inc.). All samples were assayed in triplicate and analyzed by using Prism version 5.04 (GraphPad Software Inc., San Diego, CA). Data was analyzed by one-way analysis of variance and Dunnett's multiple comparison test.

APOE levels in brain $(50 \mu \mathrm{g}$ homogenates $)$ and CSF (10 $\mu \mathrm{l})$ were analyzed by Western blot following PAGE using 4-12\% Bis-Tris gels (Invitrogen, Carlsbad, CA). Blots were probed with primary antibodies to APOE (goat polyclonal, EMD Millipore; 1:1000) and the loading control, actin (ThermoFisher Scientific; 1:200) for $60 \mathrm{~min}$ at $4^{\circ} \mathrm{C}$ and then washed with TBST (Tris-buffered saline, $0.1 \%$ Tween 20) three times at room temperature, followed by (Goatanti-mouse) secondary antibody (ThermoFisher Scientific; 1:1000) for $30 \mathrm{~min}$ at $4^{\circ} \mathrm{C}$. Densitometric analysis of ApoE was performed (exposure time of 4 minutes with a relative intensity of 2.0, Odyssey imaging system, with application software Version 3.0) followed by an unpaired t-test using GraphPad Prism 5.04 software.

Measurement of Plasma, CSF, and Brain Drug Concentration: Aliquots of plasma $(50 \mu \mathrm{l})$ were combined with $300 \mu \mathrm{l}$ of acetonitrile containing $125 \mu \mathrm{l}$ structurally related internal standard (IS), vortexed, and centrifuged. Supernatant was transferred into a plain polypropylene 96-well plate for sample analysis. Brain tissue samples were homogenized by using a Covaris (Woburn, MA) acoustic homogenizer. Aliquots of $50 \mu \mathrm{l}$ homogenate were combined with acetonitrile containing a structurally related IS, vortexed, and centrifuged at 1,900 $\mathrm{g}$ for 5 minutes. Supernatant was transferred into a 96-well plate for sample analysis. Analytical standards and tissues were measured by liquid chromatography mass spectrometry (Shimadzu Pumps Autosampler Prominence for HPLC and PE Sciex API 4000 for MS, with Analyst 1.6.1 software) using 
atmospheric-pressure chemical ionization and multiple reaction monitoring in the positive ion mode.

\section{Results}

Our aim in this study was to investigate the effects of RXR/LXR agonism on $\mathrm{A} \beta$ homeostasis in the CNS of non-transgenic rats using the RXR agonist, Bexarotene and the LXR agonist, TO901317. As a positive control, we included a $\beta$-secretase inhibitor (AMG8155). Compounds and appropriate vehicle controls were administered to naïve Sprague Dawley rats at doses indicated in Table 1 for either 3 or 7 consecutive days.

Following 3 and 7 days of dosing, animals were evaluated for both compound levels and pharmacodynamic endpoints. APOE levels were quantitated in brain homogenate and CSF by Western blot.

\section{Table 1. Dosing Table.}

\begin{tabular}{|c|c|}
\hline Group & Dose $\mathbf{( m g / k g )}$ \\
\hline Bexarotene & 100 \\
\hline AMG8155 & 3 \\
\hline T0901317 & 30 \\
\hline
\end{tabular}

Table 1 lists the 3 compounds tested in this study along with the respective doses $(\mathrm{mg} / \mathrm{kg})$.

$\mathrm{A} \beta 40$ levels were quantitated in the same compartments using immunoassay as described in the Materials and methods section. Following 3 and 7 days of dosing, APOE levels were increased in brain and CSF in the TO901317 treated animals compared to vehicle treated animals (Figure 1). Changes in CSF were statistically

A

Day 3

Day 7
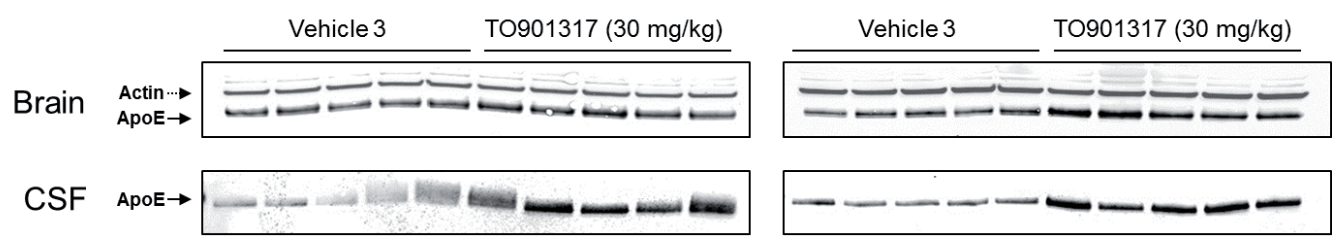

B
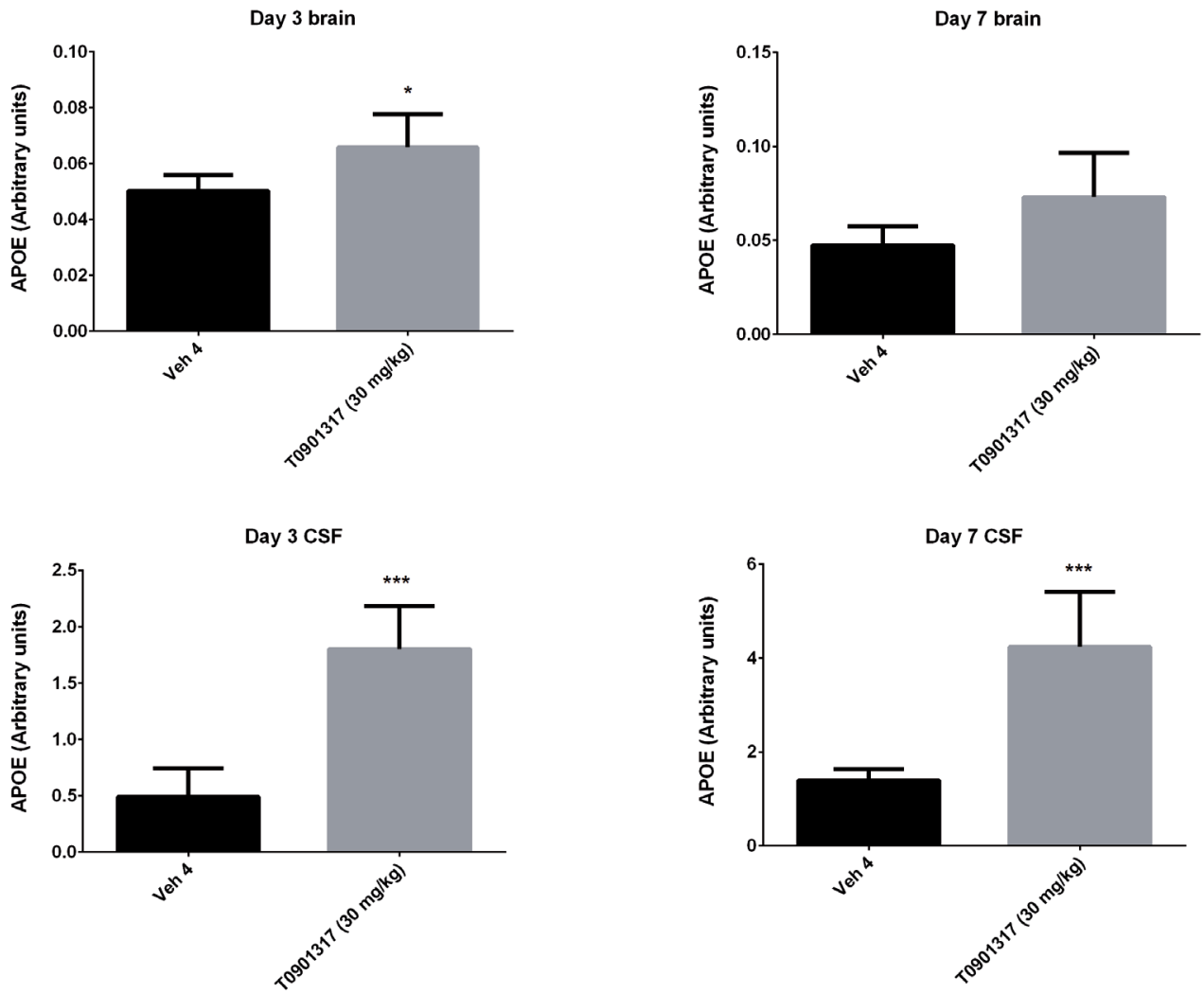

Figure 1. LXR agonist, TO901317 significantly increased APOE levels in rat CSF following 3 and 7 days of dosing at $30 \mathrm{mg} / \mathrm{kg}$. APOE was also increased in brain however the changes only reached statistical significance at day 3 . A) Western blot analysis of APOE in brain and CSF. B) Densitometric analysis of the bands was performed as described in the Materials and Methods section; data are presented as the mean plus standard deviation; Vehicle 4 (black bars) and T0901317 (gray bars). 
significant at both $3(\mathrm{p}=0.0002)$ and 7 days $(\mathrm{p}=0,0007)$ whereas changes in brain were statistically significant at day $3(p=0.030)$ but did not reach significance at day $7(\mathrm{p}=0.056)$. Bexarotene treatment also resulted in a statistically significant increase in CSF APOE levels compared to vehicle treated animals following both 3 $(p=0.019)$ and 7 days $(p=0.002)$ of dosing (Figure 2$)$. APOE levels in brain following Bexarotene treatment trended towards an increase however these changes were not statistically significant. Soluble A $\beta 40$ levels were unchanged in brain and CSF following 3-day (Figure 3) and 7-day (Figure 4) treatment with either
Bexarotene or TO901317. The positive control BACE inhibitor, AMG8155 effectively reduced $A \beta 40$ levels by $70 \%$ and $71 \%$ in CSF and by $67 \%$ and $69 \%$ in brain in the 3-day and 7-day studies respectively (Figure 3 and Figure 4).

Drug levels of Bexarotene and TO901317 were measured in plasma and brain homogenate following 3 and 7 days of dosing (Table 2). Total levels of both compounds achieved single-digit to low doubledigit $\mu \mathrm{M}$ levels in brain and showed good uptake in brain relative to plasma in both dosing paradigms.

A

Day 3

Day 7
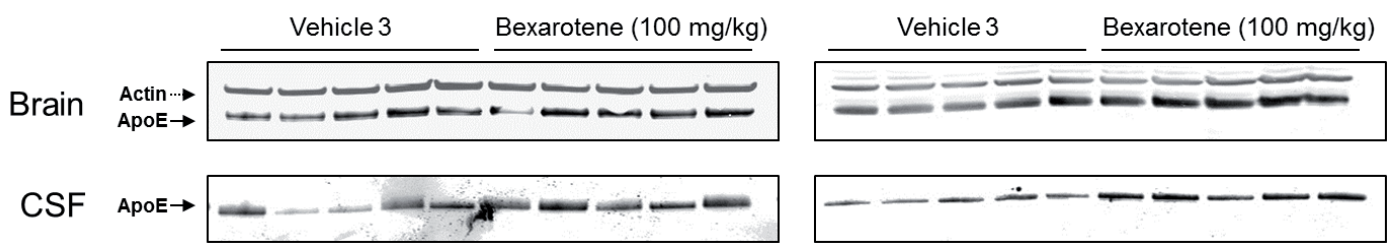

B
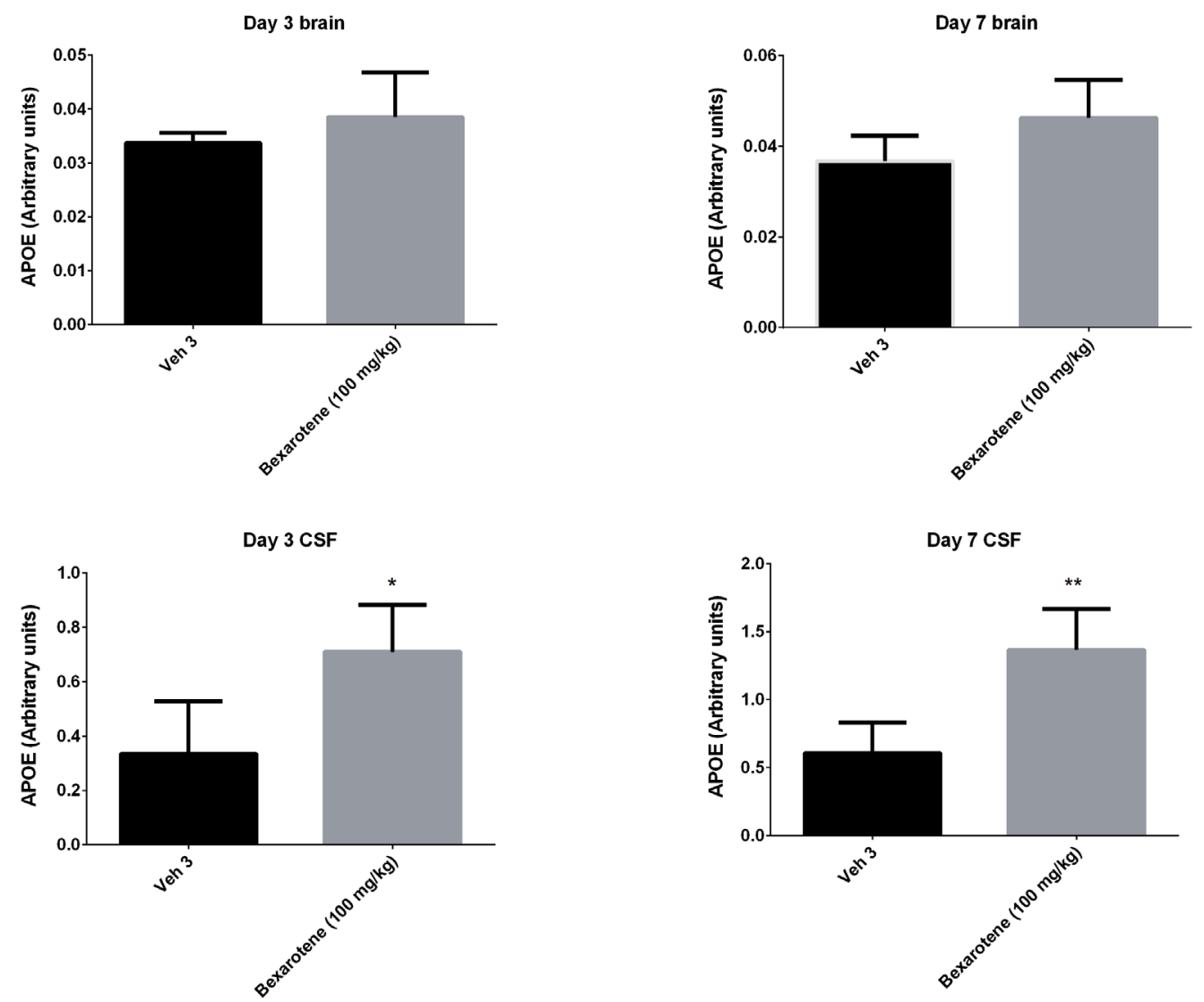

Figure 2. RXR agonist, Bexarotene significantly increased APOE in rat CSF following 3 and 7 days of dosing at $100 \mathrm{mg} / \mathrm{kg}$. APOE changes in brain were not statistically significant. A) Western blot analysis of APOE in brain and CSF. B) Densitometric analysis of the bands was performed as described in the Materials and Methods section; data are presented as the mean plus standard deviation; Vehicle 4 (black bars) and Bexarotene (gray bars). 
A

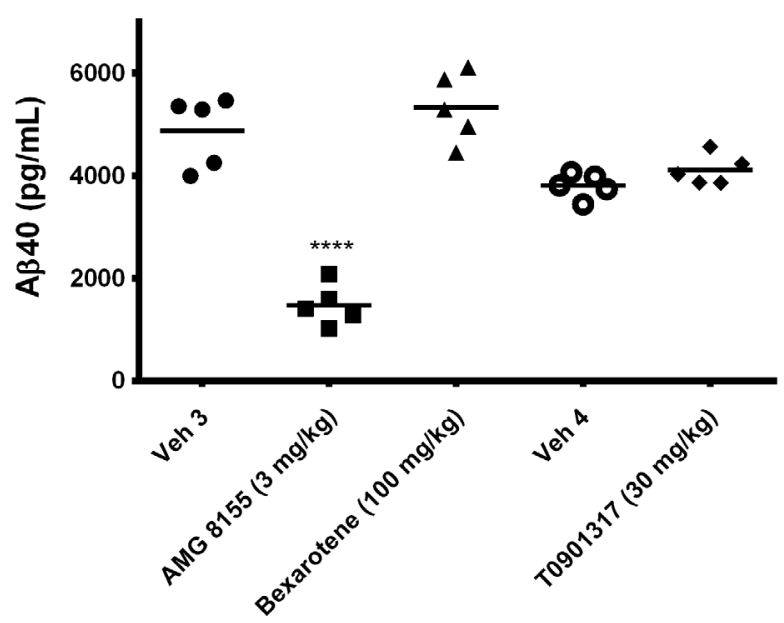

B

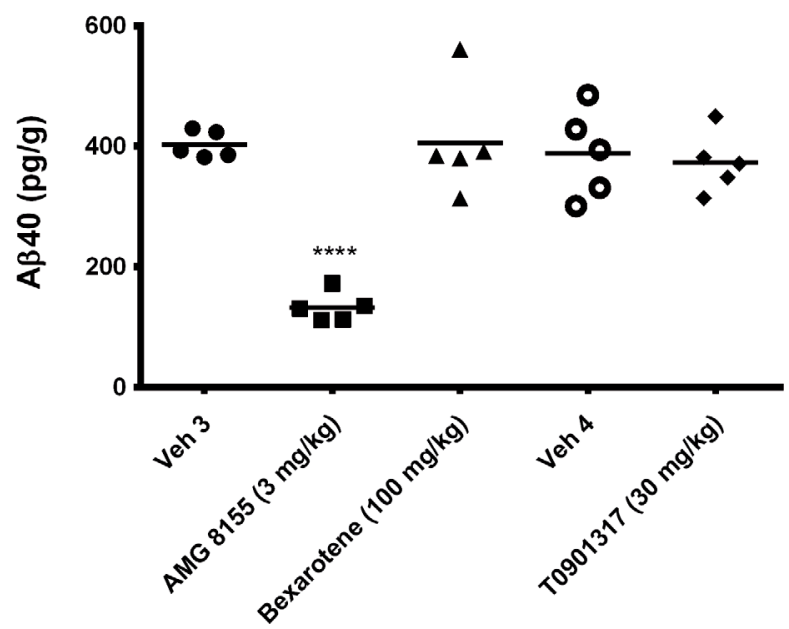

Figure 3. A 440 levels in (A) CSF and (B) brain were unchanged following 3 days of treatment with Bexarotene (triangles) or TO901317 (diamonds). Positive control BACE inhibitor AMG8155 (squares) reduced A 440 levels 70 and $67 \%$ in CSF and brain respectively following a single administration.

A

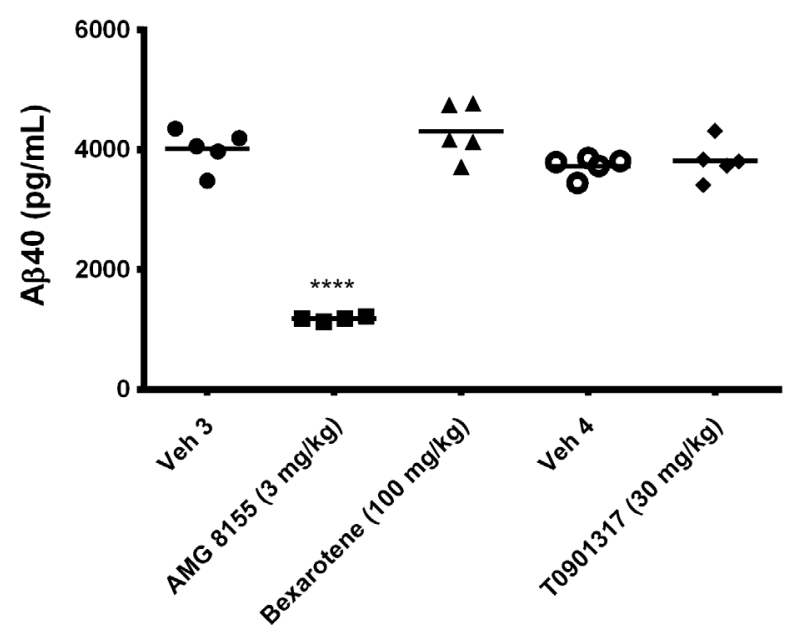

B

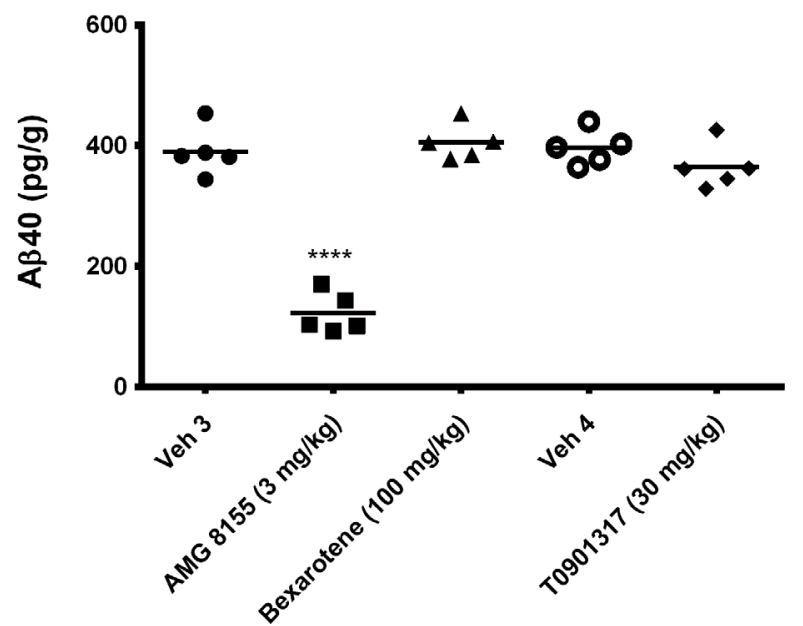

Figure 4. A 340 levels in (A) CSF and (B) brain were unchanged following 7 days of treatment with Bexarotene (triangles) or TO901317 (diamonds). Positive control BACE inhibitor AMG8155 (squares) reduced A 40 levels 71 and 69\% in CSF and brain respectively following a single administration. 


\section{Table 2. Compound Exposure Table.}

\begin{tabular}{|l|l|c|c|c|}
\hline $\begin{array}{l}\text { Treatment } \\
\text { Duration }\end{array}$ & Compound & [brain] $]_{\mathbf{t}}, \boldsymbol{\mu M}$ & [plasma], $\boldsymbol{\mu M}$ & $\begin{array}{c}\text { [brain] } \\
\text { [plasma }]_{\mathbf{t}}\end{array}$ \\
\hline 3 days & $\begin{array}{l}\text { Bexarotene } \\
(100 \mathrm{mg} / \mathrm{kg})\end{array}$ & 6.26 & 5.74 & 1.09 \\
\hline & $\begin{array}{l}\text { TO901317 } \\
(30 \mathrm{mg} / \mathrm{kg})\end{array}$ & 14.44 & 5.30 & 2.72 \\
\hline 7 days & $\begin{array}{l}\text { Bexarotene } \\
(100 \mathrm{mg} / \mathrm{kg})\end{array}$ & 3.41 & 4.76 & 0.72 \\
\hline & $\begin{array}{l}\text { TO901317 } \\
(30 \mathrm{mg} / \mathrm{kg})\end{array}$ & 11.68 & 4.30 & 2.72 \\
\hline
\end{tabular}

Following 3 and 7 days of dosing, compound levels were measure in brain homogenate and plasma. Total $(\mathrm{t})$ compound concentrations $(\mu \mathrm{M})$ are reported in each case. The brain to plasma ratio is also shown (far right-hand column).

\section{Conclusion}

In this study we demonstrate that 3-day or 7-day treatment of naïve rats with the LXR agonist, TO901317 or RXR agonist, Bexarotene treatment resulted in an increase in APOE levels in CSF. No changes were observed in CSF or brain A $\beta 40$ levels with either compound after 3 or 7 days of dosing. We hope that these findings will stimulate further discussion in the Alzheimer's research community on the impact of LXR/RXR agonism on central A $\beta$ homeostasis.

\section{Data availability}

Open Science Framework: Dataset: Effect of LXR/RXR agonism on brain and CSF A $\beta 40$ levels in rats, doi: 10.17605/OSF. IO/3NS64 ${ }^{11}$
Author contributions

S. Wang: Participated in research design; wrote or contributed to the writing of the manuscript.

P. Wen: Participated in research design; conducted experiments; performed data analysis; wrote or contributed to the writing of the manuscript.

S. Wood: Participated in research design; performed data analysis; wrote or contributed to the writing of the manuscript.

Competing interests

All authors are employees and stockholders of Amgen, Inc.

Grant information

All work was funded by Amgen Inc.
1. Citron M: Alzheimer's disease: strategies for disease modification. Nat Rev Drug Discov. 2010; 9(5): 387-98.

PubMed Abstract | Publisher Full Text

2. Hardy J, Selkoe DJ: The amyloid hypothesis of Alzheimer's disease: progress and problems on the road to therapeutics. Science. 2002; 297(5580): 353-6.

PubMed Abstract | Publisher Full Text

3. Yu JT, Tan L, Hardy J: Apolipoprotein E in Alzheimer's disease: an update. Annu Rev Neurosci. 2014; 37: 79-100. PubMed Abstract | Publisher Full Text

4. Morris $\mathrm{JC}$, Roe $\mathrm{CM}$, Xiong $\mathrm{C}$, et al: $A P O E$ predicts amyloid-beta but not tau Alzheimer pathology in cognitively normal aging. Ann Neurol. 2010; 67(1): 122-31.

PubMed Abstract | Publisher Full Text | Free Full Text

5. Chawla A, Boisvert WA, Lee $\mathrm{CH}$, et al:: A PPAR gamma-LXR-ABCA1 pathway in macrophages is involved in cholesterol efflux and atherogenesis. Mol Cell. 2001; 7(1): 161-71.

PubMed Abstract | Publisher Full Text

6. Hong C, Tontonoz P: Coordination of inflammation and metabolism by PPAR and LXR nuclear receptors. Curr Opin Genet Dev. 2008; 18(5): 461-7. PubMed Abstract | Publisher Full Text

7. Jiang Q, Lee CY, Mandrekar S, et al.: ApoE promotes the proteolytic degradation of Abeta. Neuron. 2008; 58(5): 681-93.

PubMed Abstract | Publisher Full Text | Free Full Text

8. Koldamova RP, Lefterov IM, Staufenbiel $\mathrm{M}$, et al.: The liver $\mathbf{X}$ receptor ligand T0901317 decreases amyloid beta production in vitro and in a mouse model of Alzheimer's disease. J Biol Chem. 2005; 280(6): 4079-88.

PubMed Abstract | Publisher Full Text

9. Fitz NF, Cronican $\mathrm{A}$, Pham $\mathrm{T}$, et al.: Liver $\mathrm{X}$ receptor agonist treatment ameliorates amyloid pathology and memory deficits caused by high-fat diet in APP23 mice. J Neurosci. 2010; 30(20): 6862-72.

PubMed Abstract | Publisher Full Text | Free Full Text

10. Cramer PE, Cirrito JR, Wesson DW, et al:: ApoE-directed therapeutics rapidly clear $\beta$-amyloid and reverse deficits in AD mouse models. Science. 2012; 335(6075): 1503-6. PubMed Abstract | Publisher Full Text | Free Full Text

11. Wang S, Wen PH, Wood S: Dataset: Effect of LXR/RXR Agonism on Brain and CSF A 440 Levels in Rats. Open Science Framework. 2016.

Data Source 


\section{Open Peer Review}

\section{Current Peer Review Status:}

\section{Version 1}

Reviewer Report 02 March 2016

https://doi.org/10.5256/f1000research.8469.r12696

(C) 2016 LaDu M et al. This is an open access peer review report distributed under the terms of the Creative Commons Attribution License, which permits unrestricted use, distribution, and reproduction in any medium, provided the original work is properly cited.

\section{Mary Jo LaDu \\ Department of Anatomy and Cell Biology, University of Illinois at Chicago, Chicago, IL, USA Conor Smith \\ Department of Anatomy and Cell Biology, University of Illinois at Chicago, Chicago, IL, USA \\ Ana Valencia \\ Department of Anatomy and Cell Biology, University of Illinois at Chicago, Chicago, IL, USA \\ In this manuscript, Wang and colleagues report that treatment for 3 and $7 \mathrm{~d}$ bexarotene (Bex, an RXR agonist) or T0901317 (TO, an LXR agonist) induce an increase in apoE levels and but have no effect on AB40 in the CSF and brain of rats. While the subject matter is timely, the conclusions must be taken with reservations because of three major concerns:}

1. Limited readouts and regions analyzed. It has been previously demonstrated that changes in the levels of AB40 and apoE in CSF and brain do not always correlate with efficacy in FADTg mice ${ }^{1,2}$. Furthermore, it has been shown that an increase of apoE levels by Bex can be beneficial or detrimental depending on the isoform of $\mathrm{apoE}^{3}$ or the brain region analyzed ${ }^{3}$.

2. The exclusion of $A \beta 42$. It has been reported that CSF $A \beta 42$ levels, and not $A \beta 40$, are increased in AD patients compared to controls ${ }^{4}$.

3. Comparison to previous reports. Suon and colleagues $(2010)^{5}$ treated rats with LXR agonists TO (at the same dose) or GW3965 and reported an increase in apoE that correlated with an increase in Ab40/42 levels in CSF and a reduction of A 340 in brain ${ }^{5}$. Wang and colleagues should reconcile their results with this work specifically and interpret their work in the context of the filed in general.

A minor observation is that in Figure 1A the vehicle is mislabeled as Vehicle 3 (should be Vehicle 4 for T0901317)

Within the AD field, there is an ongoing discussion of the effects of Bex on soluble and deposited A $\beta$ levels in the brain and cognition, with contradictory findings. This is likely due to several 
confounding factors, including: variance within and across models and inconsistencies in the methods used to characterize and quantify the proteins of interest, particularly soluble $A \beta$. It is imperative to take these parameters into account when considering the efficacy of RXR or LXR agonists for AD therapeutics. As well, a phase I trial of Bex in AD patients recently concluded ${ }^{6}$. While these results may be of limited significance and were not available for the submission of this manuscript, inclusion of their results in a revision of the Discussion would be helpful.

\section{References}

1. Tesseur I, Lo AC, Roberfroid A, Dietvorst S, et al.: Comment on. Science. 2013; 340 (6135): 924-e PubMed Abstract | Publisher Full Text

2. Boehm-Cagan A, Michaelson DM: Reversal of apoE4-driven brain pathology and behavioral deficits by bexarotene.J Neurosci. 2014; 34 (21): 7293-301 PubMed Abstract | Publisher Full Text 3. Tai LM, Koster KP, Luo J, Lee SH, et al.: Amyloid- $\beta$ pathology and APOE genotype modulate retinoid X receptor agonist activity in vivo.J Biol Chem. 2014; 289 (44): 30538-55 PubMed Abstract | Publisher Full Text

4. Blennow K, Mattsson N, Schöll M, Hansson O, et al.: Amyloid biomarkers in Alzheimer's disease. Trends Pharmacol Sci. 2015; 36 (5): 297-309 PubMed Abstract | Publisher Full Text

5. Suon S, Zhao J, Villarreal SA, Anumula N, et al.: Systemic treatment with liver $X$ receptor agonists raises apolipoprotein $\mathrm{E}$, cholesterol, and amyloid- $\beta$ peptides in the cerebral spinal fluid of rats.Mol Neurodegener. 2010; 5: 44 PubMed Abstract | Publisher Full Text

6. Cummings JL, Zhong K, Kinney JW, Heaney C, et al.: Double-blind, placebo-controlled, proof-ofconcept trial of bexarotene Xin moderate Alzheimer's disease.Alzheimers Res Ther. 2016; 8 (1): 4

PubMed Abstract | Publisher Full Text

Competing Interests: No competing interests were disclosed.

We confirm that we have read this submission and believe that we have an appropriate level of expertise to confirm that it is of an acceptable scientific standard, however we have significant reservations, as outlined above.

Reviewer Report 29 February 2016

https://doi.org/10.5256/f1000research.8469.r12274

(C) 2016 Gandy S. This is an open access peer review report distributed under the terms of the Creative Commons Attribution License, which permits unrestricted use, distribution, and reproduction in any medium, provided the original work is properly cited.

\section{Sam Gandy}

Department of Neurology and Psychiatry, Mount Sinai School of Medicine, New York, NY, USA

Some controversy has surrounded the report in Science from Landreth and colleagues showing that bexarotene reduces the brain amyloid plaque burden from APP transgenic mice by 50\% or more in a matter of days. Several groups of experts attempted to replicate the dramatic Landreth results but the dramatic results were not replicatable. The current F1000Research paper extends that replication attempt story by treating rats with bexarotene and then measuring APP 
metabolites and apoE in CSF. In agreement with the "second wave" of bexarotene studies, there was no effect of bexarotene on CSF levels of $A \beta 40$ or $A \beta 42$. The one point of agreement of all studies was that bexarotene does indeed modulation CSF levels of apoE. This argues against the development of bexarotene mimetics as $A \beta$ lowering agents for the treatment or prevention of Alzheimer's disease. However, inasmuch as elevating apoE may be beneficial in clinical situations via a non-Aß-dependent pathway (see http://www.alzforum.org/news/research-news/bexarotenerevisited-improves-mouse-memory-no-effect-plaques), bexarotene does reproducibly modulate CSF levels of apoE. The discovery of the entity of SNAP (for review, see Jack et al., 2016 ${ }^{1}$ ) indicates that about one-third of clinically diagnosed Alzheimer's patients undergo cognitive decline via some as yet unknown non-A $\beta$-dependent pathway.

\section{References}

1. Jack CR, Knopman DS, Chételat G, Dickson D, et al.: Suspected non-Alzheimer disease pathophysiology - concept and controversy.Nat Rev Neurol. 2016; 12 (2): 117-24 PubMed Abstract | Publisher Full Text

Competing Interests: No competing interests were disclosed.

\section{I confirm that I have read this submission and believe that I have an appropriate level of expertise to confirm that it is of an acceptable scientific standard.}

\section{Comments on this article}

\section{Version 1}

Reader Comment 11 Feb 2016

Gary Landreth, Case Western Reserve University, USA

Wang et al. have reported that they have failed to replicate the ability of bexarotene to clear soluble amyloid from the brain. The reason they failed is straightforward. This experiment has been repeated 6 times. This specific issue has been nicely summarized in a paper published by Tesseur and De Strooper (2013), who were authors of one of the 'Comments' on our Science paper. I draw your attention to the summary table in that paper. The reason Amgen was unable to reproduce our results was that they used the wrong drug formulation. We used the clinically approved formulation of bexarotene (Targretin ${ }^{\mathrm{TM}}$ ), which is a microcrystaline form of the drug. Those laboratories who used this formulation found drug-induced ApoE expression and lowered Abeta levels. Those studies that solubilized the drug prior to administration failed to replicate the published results. The micronization of bexarotene results in very different pharmacokinetic compared to solubilized drug, which was clearly documented by Chen et al. (2014; Fig 8a) and in the FDA filings. The micronized form of the drug is slowly absorbed in the gut and results in sustained plasma (and brain) levels of the drug, whereas the solubilized drug is rapidly absorbed and cleared. The reason this is important is based on the well known mechanisms of nuclear receptor action. Nuclear receptors, like RXR, are ligand-activated transcription factors. Ligand binding to the receptor results in assembly of chromatin remodeling machinery on the enhancers and promoters of its target genes, resulting in epigenetic modifications that open chromatin structure, allowing 
induction of gene expression. This process takes time, thus there must be sufficiently high drug levels over an extended interval in order for this to be achieved.

The formulation issue was explicitly discussed in the literature and the FDA filing for bexarotene and was detailed on our 'Response' to the 'Comments' in Science (Landreth et al., 2013). The Amgen scientists (and others) clearly did not make an effort to understand and replicate the original study design, nor appreciate the importance of the formulation of the drug as it relates to nuclear receptor action. Although the Amgen study was narrowly focused on ApoE and soluble Abeta 40 and did not examine other aspects of our work, the same considerations apply to other contested outcomes of our study.

The Amgen study employed wild type Sprague-Dawley rats, whereas all other studies with bexarotene used murine models of AD. A study of the LXR agonist T09001317 in rats that was similar to that of Amgen was published by Merck (Suon et al., 2010) and was only partially replicated in the Amgen study and was not cited.

Our work on bexarotene has led to clinical examination of its effects in Alzheimer's disease. Cummings and colleagues published the outcome of a phase II study of bexarotene in mild to moderate AD patients last week (Cummings et al., 2016). While bexarotene treatment did not have a demonstrable effect in individuals possessing an ApoE4 allele, individuals that did not have an ApoE4 gene (representing about $80 \%$ of the population) exhibited a robust reduction in brain amyloid with a parallel appearance of Abeta42 in plasma. Thus, a brief 30 day treatment altered two canonical biomarkers of $A D$ in patients with diagnosed disease. These findings are consonant with a recent case report reporting cognitive improvement with bexarotene treatment (Pierrot et al. 2015). I hasten to add that the small study size precludes making any hard conclusions from this trial and they should be interpreted cautiously. However, these preliminary clinical findings support and validate our original report using mouse models of the disease.

I don't think the Amgen study adds anything to what was previously known. The work has a logical flaw that undermines the conclusion that they were unable to repeat our study outcomes, including the use of a different model. I think this study is emblematic of the problems associated with reporting 'failure to replicate' findings in studies that do not genuinely reproduce the published work.

Competing Interests: No competing interests were disclosed. 
The benefits of publishing with F1000Research:

- Your article is published within days, with no editorial bias

- You can publish traditional articles, null/negative results, case reports, data notes and more

- The peer review process is transparent and collaborative

- Your article is indexed in PubMed after passing peer review

- Dedicated customer support at every stage

For pre-submission enquiries, contact research@f1000.com 